\title{
Transformações antrópicas da paisagem agrícola com palma de óleo no Pará
}

\section{Anthropogenic transformations of the agricultural landscape with oil palm in Pará}

Arlete Silva Almeida - Doutora em Ciências Ambientais, pela Universidade Federal do Pará (UFPA). Tecnóloga do Ministério de Ciências e Tecnologia lotada no Museu Paraense Emílio Goeldi (MPEG). E-mail: arlete@museu-goeldi.br

Ima Célia Guimarães Vieira - Doutora em Ecologia pela University of Stirling. Pesquisadora titular do Museu Paraense Emilio Goedi (MPEG). E-mail: ima@museu-goeldi.br.

\section{Resumo}

Este estudo teve como objetivo identificar os principais usos da terra e determinar o nível de antropização da paisagem em áreas de expansão do dendezeiro (Ubá, Arauai e Mamorana), nos anos de 2013 e 2017, no leste do Pará. Utilizaram-se imagens do satélite Landsat 8, de 2013 e 2017. E a classificação dos usos da terra foi realizada por meio do método árvore de decisão. A pressão antrópica foi analisada por meio do Índice de Transformação Antrópica (ITA) que foi considerado regular e degradado em todas as áreas, nos dois anos analisados. A área de maior pressão foi Arauai e Ubá a de menor pressão. O desmatamento da floresta primária e a expansão da agropecuária e da palma de óleo evidenciam as maiores pressões na paisagem e a necessidade de controle e preservação dos remanescentes florestais no território analisado.

\section{Palavras-chave}

Mudanças Ambientais. Pressão Antrópica. Geotecnologias. Desflorestamento.

\begin{abstract}
This study aimed to identify the main land uses and determine the level of landscape anthropization in oil palm expansion areas (Ubá, Arauai and Mamorana), in the years 2013 and 2017, in eastern Pará. We used Landsat 8 satellite images from 2013 and 2017. The land uses were classified using the decision tree method. Anthropic pressure was analyzed using the Anthropic Transformation Index (ITA), which was considered regular and degraded, in the areas. The area with the highest pressure was Arauai and Ubá is the area with the lowest pressure. Deforestation of the primary forest and the expansion of agriculture and palm oil, were the main pressures and we confirm the need for control and preservation of forest remnants in the analyzed territory.
\end{abstract}

\section{Keywords}

Environmental Changes. Anthropic

Pressure. Geotechnologies. Deforestation 


\section{INTRODUÇÃO}

$\mathrm{Na}$ Amazônia, historicamente, a incorporação de novas áreas ao processo produtivo ocorreu às expensas de florestas nativas. Em um período de 29 anos (1988 a 2017) o desmatamento da floresta amazônica alcançou $428.721 \mathrm{~km}^{2}$ (INPE, 2017), sendo o estado do Pará o que mais perdeu cobertura florestal nesse período. A pecuária e a expansão da agricultura são os principais propulsores do desmatamento na região, seja por conversão direta ou pelo deslocamento indireto do uso da terra (ALVES et al., 2009; RIVERO et al., 2009). Os padrões de mudanças de usos da terra são extremamente heterogêneos em termos espaciais e temporais, uma vez que, após o desmatamento da floresta primária, as pastagens $(62 \%)$ e a vegetação secundária $(21 \%)$ predominam na paisagem regional (ALMEIDA et al., 2014).

A partir de 2010, a expansão do dendezeiro (palma de óleo) no estado do Pará foi impulsionada pelo aumento da demanda por alimentos e biocombustíveis (HOMMA; VIEIRA, 2012) e, em função disso, foi estabelecida neste estado uma nova fronteira de expansão da palma de óleo, com mecanismos para facilitar a inserção da agricultura familiar no processo produtivo visando o desenvolvimento sustentável, diminuir o conflito com o desmatamento de florestas e priorizar a utilização de áreas degradadas para a expansão da cultura, no âmbito do Programa de Produção Sustentável de Palma de Óleo (PPSPO) (BRANDÃO; SCHONEVELD, 2015). Assim, de 2010 a 2016, o plantio da palma aumentou de $600 \mathrm{~km}^{2}$ para 1.940 $\mathrm{km}^{2}$ no estado do Pará (HOMMA; VIEIRA, 2012) e noventa por cento dessa expansão ocorreu em terras ocupadas por pastagens (BENAMI et al., 2018).

Para acompanhar essa nova dinâmica produtiva com palma de óleo, são necessários estudos que contribuam para identificar as mudanças socioambientais associadas à nova frente agrícola decorrente dessa produção. Estudos demonstram diversos riscos da expansão desses cultivos, tais como o uso de remanescentes florestais (LEES et al., 2015), a contaminação dos rios e do solo por agrotóxicos (BRANDÃO; SCHONEVELD, 2015), a desapropriação de terras e conflitos com populações tradicionais (NAHUM; SANTOS 2015), a legitimação do uso da terra pelo setor agroindustrial do óleo de palma (green grabbing) (BACKHOUSE, 2013), a insegurança alimentar e o empobrecimento da biodiversidade (ALMEIDA, 2015). Assim, consideramos que a palma de óleo é uma cultura de alto impacto (LEES et al., 2015), e a sua expansão requer uma avaliação dos efeitos potenciais dessa monocultura na paisagem. 
Neste contexto, o objetivo deste estudo foi identificar os principais usos da terra e analisar o nível de antropização da paisagem em áreas de expansão do dendezeiro nos anos de 2013 e 2017, no leste do Pará, por meio do Índice de Transformação Antrópica (ITA). Este índice foi desenvolvido por Lémechev (1982) para quantificar a pressão antrópica na paisagem e fornecer informações para o planejamento territorial em diferentes escalas. Nossa hipótese é a de que a expansão recente do dendezeiro ocorre de forma intensa e propicia elevada transformação antrópica na paisagem.

\section{MATERIAL E MÉTODO}

\section{1 ÁREA DE ESTUDO}

As áreas de estudo foram delimitadas a partir de três recortes espaciais de uma região de expansão da palma, localizada nos municípios de Moju, Acará e Tailândia, na mesorregião do Nordeste Paraense, doravante referida como região de Moju. Tais recortes foram baseados nas seguintes características: 1) ano que começou a expansão da palma de óleo em grande escala; e 2) área com intensa fragmentação. Essas áreas foram nomeadas pelos principais rios existentes na região, ou seja: 1 - Ubá $\left(-2,35^{\circ}-48,60^{\circ}\right.$ e -2,03-48,86 $)$ com 958,23 km²; 2- Arauaí $\left(-2,81^{\circ}-48,82^{\circ}\right.$ e $\left.-2,50^{\circ}-49,07^{\circ}\right) \operatorname{com} 951,37 \mathrm{~km}^{2}$ e $3-$ Mamorana $\left(-3,06^{\circ}-49,10^{\circ}\right.$ e $\left.-2,76^{\circ}-49,28^{\circ}\right) \operatorname{com} 679,09 \mathrm{~km}^{2}$. Os recortes espaciais abrangeram uma área total de $2588,72 \mathrm{~km}^{2}$ (Figura 1).

As características fisiográficas das áreas compreendem relevo com compartimentação discreta: platôs baixos (tabuleiros), terraços fluviais e várzeas. Os tabuleiros apresentam-se aplainados e recobertos por depósitos inconsolidados, os terraços fluviais são superfícies planas ou levemente inclinadas formando as margens de um rio e as várzeas são áreas de planícies inundáveis invadidas por enchentes sazonais. O clima característico é o quente e úmido, com temperaturas médias mensais de $25^{\circ} \mathrm{C}$ a $27^{\circ} \mathrm{C}$. A precipitação pluviométrica local varia entre 2 a $3 \mathrm{mil} \mathrm{mm/ano,} \mathrm{sendo} \mathrm{o} \mathrm{período} \mathrm{de} \mathrm{janeiro} \mathrm{a} \mathrm{junho} \mathrm{a} \mathrm{época}$ mais chuvosa. A vegetação dessas áreas é composta de floresta densa de planície aluvial nas áreas de várzea, floresta secundária latifoliada de terra firme e floresta densa de baixos platôs e terraços (IDESP, 2013). 
Figura 1 - Localização da área de estudo com o recorte das áreas 1- Ubá, 2Arauaí e 3-Mamorana, na região de Moju-PA

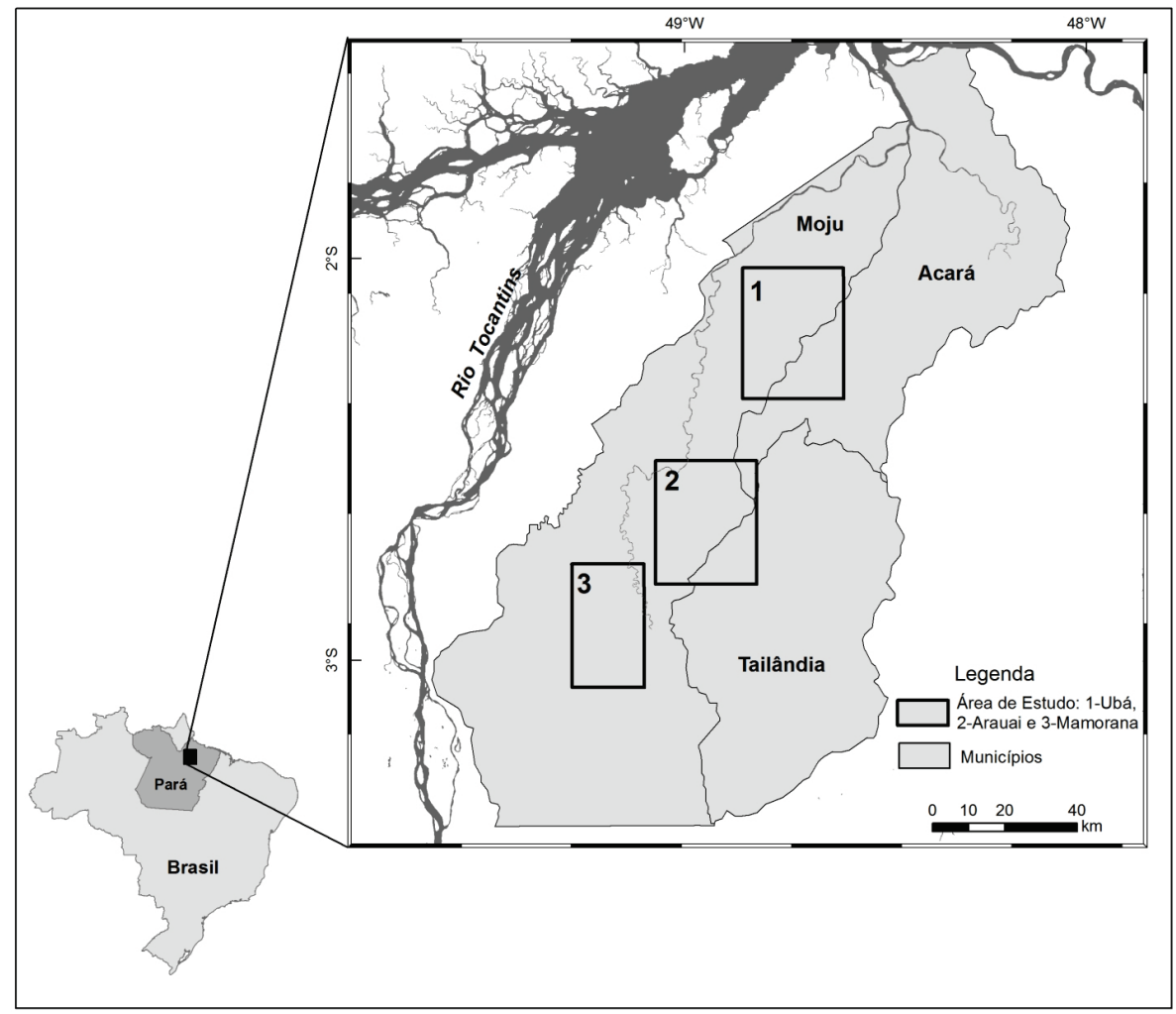

Fonte: Elaboração dos Autores.

\subsection{COBERTURA VEGETAL E USO DA TERRA}

\subsubsection{Processamento digital}

Foram utilizadas as imagens do satélite Landsat-8, de 2013 e 2017, do Serviço de Levantamento Geológico Americano (USGS, 2013, 2017), sensor OLI (Operational Land Imager), órbita/ponto 223-062 e 224-062, com projeção Geographic Coordinate System (GCS) e datum World Geographic System 1984 (WGS 84). Contemplou-se, também, as bandas 4 (vermelho), 5 (infravermelho próximo) e 6 (infravermelho médio), com resolução espacial de $30 \mathrm{~m}$, imagens ortorretificadas. A Figura 2 apresenta a imagem de 2017, com a composição colorida 6R5G4B, das áreas em estudo. 
Figura 2 - Imagem de satélite Landsat 8 , ano de 2017 das áreas 1- Ubá, 2- Arauaí e 3-Mamorana, na região de Moju-PA
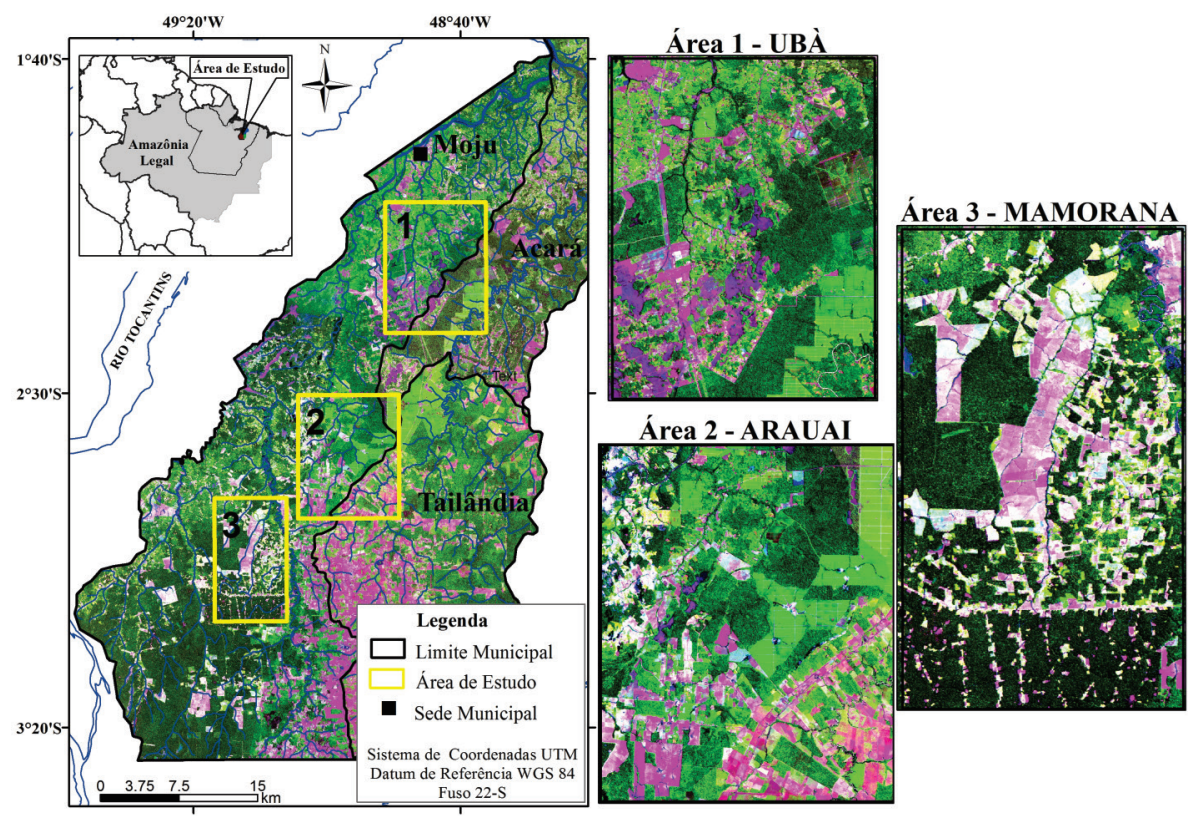

Fonte: Elaboração dos Autores.

Uma biblioteca espectral foi elaborada, a qual consiste no reconhecimento de componentes espectrais puros para calcular a abundância em cada pixel. Desses componentes de interesses, elegeram-se os pixels puros de vegetação $(\mathrm{GV})$, vegetação não fotossinteticamente ativa (NPV), índice de fração diferencial normalizada (NDFI), solo exposto, nuvem e sombra. Após esse processamento, identificou-se a curva espectral potencial para a escolha final do conjunto desses componentes espectrais puros, por meio do SMA (análise de mistura espectral) proposto por Adams (1995). Para a classificação desses componentes, foi utilizado o método de árvore de decisão (GV, NPV, NDFI, solo exposto e nuvem) como variável de regra. Os programas utilizados foram o ImgTools 2,0 (SOUZA JR.; SIQUEIRA, 2013) e o ENVI 4,5 (GARDNER et al., 2013).

\subsubsection{Definição das classes mapeadas}

Foram mapeadas as classes de floresta primária (terra firme e igapó), campinarana, floresta degradada (áreas com extração madereira), floresta 
secundária (inicial e avançada), plantio de dendezeiro, agropecuária (pastagem e gricultura temporária), água, nuvem e sombra. Essas mesmas classes são comuns em estudos no leste da Amazônia, onde há mosaicos agrícolas, áreas de vegetação secundária, pastagem/agricultura temporária e floresta (ALMEIDA; VIEIRA, 2008). Mesmo adotando critérios em escolher as amostras de treinamento para adequadas classificações de cada classe, geralmente, há muita confusão nas classes mapeadas, quer seja devido a limitações técnicas do sistema de aquisição, quer seja pela semelhança espectral de determinados alvos da imagem. Dessa forma, o uso da ferramenta ClassEdit, presente no ENVI, tornou-se de grande valia para a edição e análise de erros advindos do processo digital de classificação. Esse método foi aplicado por Almeida et al. (2014a).

\subsubsection{Validação do mapeamento}

Para se garantir a qualidade das informações espaciais, é indispensável que sejam realizados testes para assegurar a acurácia dos dados, uma vez que é praticamente impossível que não haja erro no mapeamento. Desse modo, um dos procedimentos é determinar os erros de comissão e omissão. O erro de comissão, por sua vez, é a não interpretação de pontos ou pixels existentes no terreno, enquanto o erro de omissão é o decorrente da interpretação de pontos ou pixel que não existem no terreno e que variam entre 0 e 1 (maior erro) (SILVA, 1999).

Nesse sentido, para as avaliações mais elaboradas sobre a veracidade da classificação espaciais, utilizou-se o cálculo do índice de Kappa (HUDSON; RAMM, 1987), que mede a acurácia dos dados espaciais, utilizando uma matriz de erro, a qual correlaciona as classes identificadas no mapeamento com as classes identificadas no trabalho de campo. Os valores resultantes da utilização desse método podem variar entre "zero" e "um", onde a tendência para valores menores indica não haver nenhuma similaridade entre os resultados das unidades da paisagem. Os valores próximos de "um" indicam haver uma grande similaridade entre os mesmos. Estes valores foram agrupados por Landis e Koch (1977), como mostra a Tabela 1. 
Tabela 1 - Qualidade da classificação associada aos Índice de Kappa

\begin{tabular}{c|c}
\hline Valor de Kappa & $\begin{array}{c}\text { Qualidade do Mapa de Cobertura e } \\
\text { Uso da Terra }\end{array}$ \\
\hline$<0.00$ & Péssima \\
\hline $0,00-0.20$ & Ruim \\
\hline $0,21-0.40$ & Razoável \\
\hline $0,41-0.60$ & Boa \\
\hline $0,61-0.80$ & Muito Boa \\
\hline $0,81-1.00$ & Excelente \\
\hline
\end{tabular}

Fonte: Landis e Koch (1977 p.165).

\subsection{AVALIAÇÃO DA PRESSÃO ANTRÓPICA}

Empregou-se, neste estudo, o Índice de Transformação Antrópica (ITA) proposto por Lémechev (1982) e modificado por Mateo (1991) e Teixeira e Cruz (2005), cujo objetivo é avaliar a pressão antrópica em uma determinada região (ROCHA; CRUZ, 2009). O índice foi calculado com base no resultado das classificações de 2013 e 2017. Tais classes temáticas receberam um peso que variou de 1 a 10, em que o menor valor indica menor pressão e, o maior valor, significa uma maior pressão (CRUZ et al., 1998; NOGUEIRA et al., 2001; GOUVEIA; GALVANIN; NEVES, 2013). Assim sendo:

$$
\mathrm{ITA}=\sum(\% \text { USO } * \mathrm{PESO}) / 100
$$

Em que:

- USO é a área em valores percentuais de cada classe de coberturas e uso da terra;

- PESO é o valor atribuído aos tipos de cobertura vegetal e uso da terra quanto ao grau de alteração antrópica.

- Varia de 1 a 10, em que 10 indica as maiores pressões.

Dessa forma, foram definidos os valores dos pesos para cada classe mapeada de acordo com sua contribuição na alteração da paisagem. Nesse aspecto, considerando o tipo de cobertura vegetal e o uso da terra encontrados no município de Moju, aplicou-se o método Delphi, no qual é realizada uma consulta sistemática interdisciplinar com diversos pesquisadores (especialistas do Museu Emílio Goeldi - Coordenação de Ciências da Terra (COCTE)), com domínio na temática, para 
um efetivo consenso sobre o peso que as classes poderiam ter, a partir do nível de modificação da paisagem (SCHWENK; CRUZ, 2008). Os pesos de cada classe de uso e cobertura vegetal estão definidos na Tabela 2.

Tabela 2 - Pesos atribuídos às classes de cobertura e uso da terra, mapeados na região de Moju-PA

\begin{tabular}{|c|c|c|}
\hline Classes & Pesos* & Características \\
\hline $\begin{array}{l}\text { Floresta } \\
\text { primária-FP }\end{array}$ & 1 & $\begin{array}{l}\text { Floresta que agrupa tipologias florestais como floresta } \\
\text { ombrófila densa (aluvial, terras baixas e submontana) e } \\
\text { floresta ombrófila aberta (cipós), é caracterizada por espécies } \\
\text { de fanerófitos, lianas lenhosas e epífitas em abundância, } \\
\text { apresenta altura de } 30 \text { a } 40 \text { m e árvores relativamente grossas } \\
\text { e dossel emergente (IBGE, 1991). }\end{array}$ \\
\hline $\begin{array}{l}\text { Campinarana- } \\
\text { CA }\end{array}$ & 2 & $\begin{array}{l}\text { Campinarana significa "falso campo", desempenha } \\
\text { importante papel na ocorrência da vegetação oligotrófica, } \\
\text { daí o enfatizar-se a expressão vegetação de influência pluvial } \\
\text { (IBGE, 1992). }\end{array}$ \\
\hline $\begin{array}{l}\text { Floresta } \\
\text { degradada-FD }\end{array}$ & 3 & $\begin{array}{l}\text { A classe floresta degradada ou explorada é caracterizada } \\
\text { como áreas florestais nas quais houve intervenção humana } \\
\text { para a extração seletiva de madeira, facilitada pela abertura } \\
\text { de estradas e construção de pátios de estocagem (LAMB; } \\
\text { GILMOUR, 2003). }\end{array}$ \\
\hline $\begin{array}{l}\text { Palma de } \\
\text { óleo-OP }\end{array}$ & 5 & $\begin{array}{l}\text { A classe palma de óleo, dendê ou dendezeiro é uma das } \\
\text { oleaginosas de origem africana mais produtiva do mundo e } \\
\text { com bom desenvolvimento em regiões tropicais, denominada } \\
\text { por Elaeis guineenses Jacq (EMBRAPA, 1995). }\end{array}$ \\
\hline $\begin{array}{l}\text { Floresta } \\
\text { secundária-FS }\end{array}$ & 6 & $\begin{array}{l}\text { A classe floresta secundária ou capoeira é resultante de um } \\
\text { processo de sucessão em áreas onde, no passado, houve } \\
\text { corte raso da floresta primária (IBGE, 1992; BARLOW et } \\
\text { al., 2007). }\end{array}$ \\
\hline $\begin{array}{l}\text { Agropecuária- } \\
\text { AG }\end{array}$ & 9 & $\begin{array}{l}\text { A classe Agropecuária destina-se à prática da agricultura ou } \\
\text { da pecuária. Devido às dificuldades em separá-las através } \\
\text { de interpretações de sensoriamento remoto, optou-se por } \\
\text { englobá-las em uma só classe. As pastagens, que são em } \\
\text { maior extensão, servem de pastoreio do gado em criação } \\
\text { extensiva e as áreas agrícolas, com culturas de ciclo curto } \\
\text { (mandioca, milho, arroz, etc.) ou ciclo longo (coco, laranja, } \\
\text { seringueira etc.) (EMBRAPA, 1995). }\end{array}$ \\
\hline
\end{tabular}

Fonte: Elaboração dos Autores.

A classificação do ITA foi baseada em Cruz et al. (1998), que determina a classificação em valores de 0 a 10; escala esta que define a situação ambiental quanto à pressão que um determinado ambiente está submetido, ou seja, quando os valores 
se aproximam de 0 a pressão apresenta-se com menor intensidade e quando se aproxima do 10 a pressão se apresenta com maior intensidade (Tabela 3).

Tabela 3 - Qualidade de classificação do ITA em menor e maior pressão antrópica

\begin{tabular}{c|l|c}
\hline Intensidade ITA & \multicolumn{1}{c|}{ Classificação } & Pressão \\
\hline $0-2,5$ & Pouco degradada & Menor \\
\hline $2,5-5,0$ & Regular & \\
\hline $5,0-7,5$ & Degradada & Maior \\
\hline $7,5-10$ & Muito degradada & \\
\hline
\end{tabular}

Fonte: Cruz et al. (1998).

\section{RESULTADOS}

Mediante o exposto, foram definidas sete classes de cobertura e usos da terra: floresta primária (FP), floresta degradada (FD), floresta secundária (FS), campinarana (CA), agropecuária (AG), palma de óleo (PO), água e nuvem/ sombra. Como houve dificuldade de separar as classes pastagem, solo exposto e culturas temporárias, então, optou-se em associá-las em uma única classe denominada de "agropecuária".

Para a validação da classificação considerou-se as classes mais expressivas como FP, FD, FS, PO e AG como mostra a Tabela 4. Tal fato possibilitou valores do Índice de Kappa com 0,92, então, percebe-se por esse alto valor que a classificação foi satisfatória, com número suficiente de amostras utilizadas para a classificação (Tabela 1).

A Tabela 4 apresenta a distribuição das classes de cobertura vegetal e o uso da terra para os anos de 2013 e 2017, bem como o nível de pressão antrópica ITA nas três áreas (Ubá, Arauai e Mamorana). Observou-se que houve perda de floresta primária em todas as áreas analisadas, principalmente em Mamorana, que está localizada na parte sul do município, bem distante da sede municipal e com pouca fiscalização ambiental.

No que se refere à distribuição de perdas e ganhos de áreas das classes mais expressivas da cobertura vegetal e uso da terra, observa-se que a floresta degradada aumentou e a floresta primária diminuiu de extensão. Em Arauai, a agropecuária e a palma de óleo perderam e ganharam áreas, respectivamente, e em Mamorana, observa-se expressiva perda de floresta primária. 
Tabela 4 - Distribuição das classes de usos da terra e ITA em 2013 e 2017 das áreas Ubá, Arauai e Mamorana, na região de Moju-PA; floresta primária-FP, campinarana-CA, floresta degradada-FD, palma de óleo-PO, floresta secundáriaFS, agropecuária-AG, outros (água/nuvem/sombra)

\begin{tabular}{l|c|c|c|c|c|c|c|c|c|c|c|c}
\hline \multirow{2}{*}{$\begin{array}{c}\text { Ano/ } \\
\text { Local }\end{array}$} & \multicolumn{9}{|c|}{2013} & \multicolumn{6}{c|}{2017} \\
\cline { 2 - 14 } Classes & $\begin{array}{c}\text { Ubá } \\
\%\end{array}$ & \multicolumn{2}{|c|}{ Arauai } & \multicolumn{2}{c|}{ Mamorana } & \multicolumn{2}{c|}{ Ubá } & \multicolumn{2}{c|}{ Arauai } & \multicolumn{2}{c}{ Mamorana } \\
\hline FP & 29,73 & 0,3 & 16,41 & 0,16 & 32,24 & 0,32 & 21,12 & 0,21 & 15,04 & 0,15 & 15,47 & 0,15 \\
\hline CA & 5,36 & 0,11 & 0,91 & 0,02 & 0,2 & 0 & 6,21 & 0,12 & 0,89 & 0,02 & 0,11 & 0 \\
\hline FD & 13,52 & 0,41 & 20,16 & 0,6 & 17,59 & 0,53 & 22,12 & 0,66 & 25,55 & 0,77 & 26,07 & 0,78 \\
\hline PO & 11,88 & 0,59 & 17,65 & 0,88 & 4,33 & 0,22 & 12,6 & 0,63 & 21,32 & 1,07 & 5,05 & 0,25 \\
\hline FS & 13,47 & 0,81 & 10,72 & 0,64 & 10,17 & 0,61 & 7 & 0,42 & 8,17 & 0,49 & 19,96 & 1,2 \\
\hline AG & 24,86 & 2,24 & 33,75 & 3,04 & 31,08 & 2,8 & 30,24 & 2,72 & 28,33 & 2,55 & 32,91 & 2,96 \\
\hline Outros & 1,18 & 0 & 0,4 & 0 & 4,39 & 0 & 0,72 & 0 & 0,7 & 0 & 0,43 & 0 \\
\hline Total & 100 & 4,46 & 100 & 5,34 & 100 & 4,52 & 100 & 4,77 & 100 & 5,04 & 100 & 5,35 \\
\hline
\end{tabular}

Fonte: Elaboração dos Autores.

O ITA teve como resultado para as áreas analisadas em 2013 um índice classificado como: regular em Ubá e Mamorana; e degradado em Arauai. Já em 2017, nota-se um índice de antropização mais acentuado em Mamorana (Figura 3).

Figura 3 - Distribuição de perdas e ganhos de áreas das classes mais expressivas da cobertura vegetal e uso da terra (floresta primária-FP, floresta degradadaFD, floresta secundária-FS, agropecuária-AP, palma de óleo-PO), em 4 anos de análise (2013-2017), em três áreas da região de Moju-PA

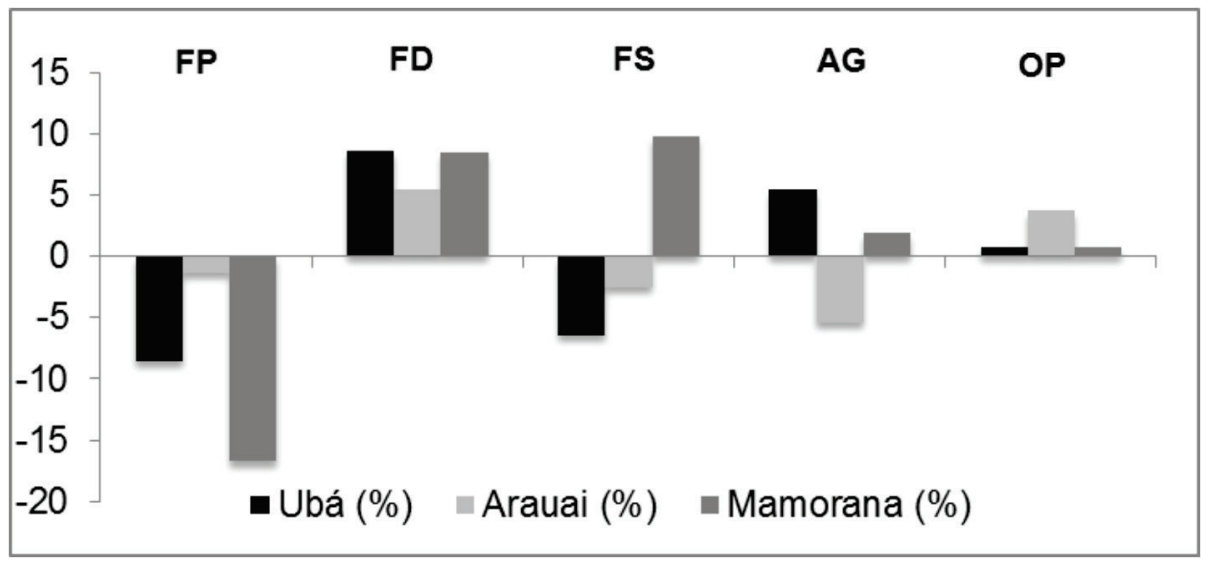

Fonte: Elaboração dos Autores. 
A Figura 4 revela o comportamento do ITA nas três áreas analisadas no período de quatro anos. Em Ubá foi obtido um índice de 4,45 (2013) e 4,77 (2017), enquanto em Mamorana obteve 4,52 (2013) e 5,35 (2017), portanto, essas áreas apresentaram menor pressão sobre o ambiente, ou seja, desempenho regular. Já Arauai, com 5,35 (2013) e 5,04 (2017), apresentou maior pressão antrópica o que caracteriza desempenho degradado.

Figura 4 - Índice de transformação antrópica (ITA) das áreas Ubá, Arauai e Mamorana, nos anos 2013 e 2017, região de Moju-PA

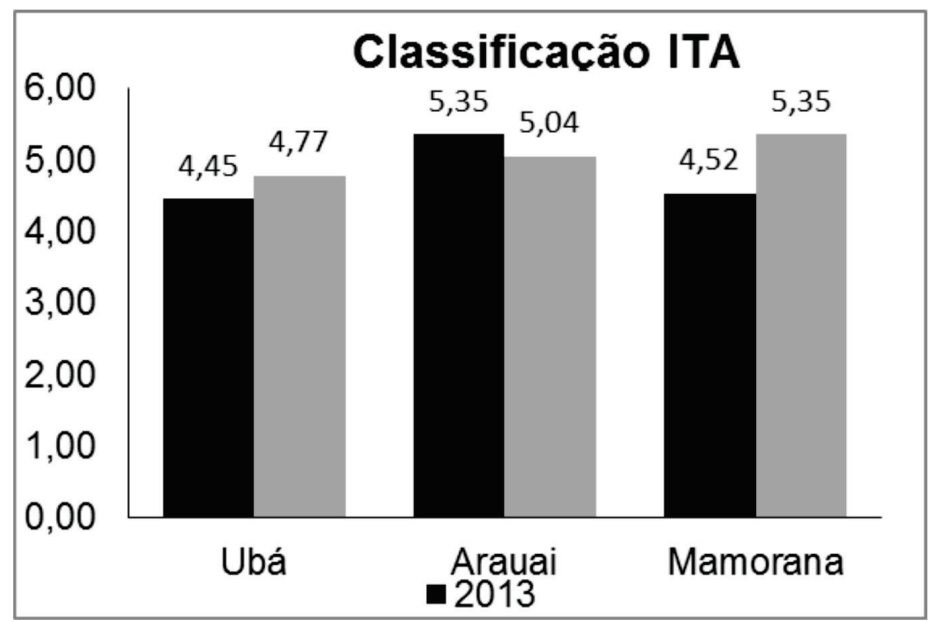

Fonte: Elaboração dos Autores.

\section{DISCUSSÃO}

A perda de floresta primária nas áreas estudadas demonstra que mesmo após a implementação de uma política nacional voltada para o desenvolvimento de práticas sustentáveis de produção, neste caso o PPSPO, ainda ocorre desmatamento de remanescentes florestais, que persistem na paisagem agrícola da região de Moju. Como o Código Florestal exige que 50\% de uma área privada estejam com floresta nativa e as áreas estudadas apresentam entre 15 a 21\% de florestas nativas, percebe-se que a região está bem abaixo dessa exigência. A perda de floresta nativa traz consequências na disponibilidade de recursos naturais, compromete os serviços ambientais e afeta diretamente a diversidade biológica (LEES et al., 2015). Para Vieira, Silva e Toledo (2005), a perda contínua de florestas pode limitar o potencial de restauração da vegetação nativa em paisagens muito antropizadas. 
A partir desses resultados, pode-se afirmar que a floresta primária continua sendo desmatada (Tabela 4), o que confirma os resultados de Almeida (2015), analisando as mesmas áreas no período de 1991 a 2013, de perdas de florestas primárias na proporção de $25,93 \%$ da área analisada. A autora afirma que parte dessa perda está relacionada com a implantação do plantio de dendezeiro, que vem ocorrendo desde 1982, quando a empresa Agropalma, antes denominada Companhia Real Agroindústrial S. A. (CRAI), expandiu o plantio e extração de óleo de palma e de palmiste na microrregião de Tomé-Açu. Em Ubá estão as três empresas mais expressivas em produção de palma de óleo: Biopalma, Agropalma e Marborges, localizadas próximo a PA-150, o que favorece o escoamento da produção. O plantio de dendezeiro ocorreu historicamente em áreas com melhores condições de escoamento da produção e criou o mercado de terras com condições territoriais para a implantação das empresas (NAHUM; SANTOS, 2015).

A maior perda de floresta primária, em 2017, ocorreu em Mamorana com diminuição acima de 16\%, o que demonstra mudanças no ambiente de forma intensa (Figura 3). A esse respeito, Almeida e Vieira (2014), em 2010, observaram que em Moju, as transformações ambientais são bastante dinâmicas, haja vista existir muita retirada de floresta para uso de pastagem e/ou plantio de dendezeiro. De acordo com a Pesquisa da Pecuária Municipal (PPM, 2018), Moju apresentou, em 2017, um efetivo de cabeças de gado de 80.756. De fato, a agropecuária apresentou área superior a de florestas primárias nas três áreas e anos analisados, sendo que em Mamorana essa classe domina cerca de 33\% de área (Tabela 4).

A floresta secundária diminui nas áreas de Uba em uma proporção de 6,46\% e em Arauai de 2,55\%, mas para a área Mamorana houve um aumento de 9,79\% (Tabela 4). Essa floresta apresenta diferente estágio de sucessão, sendo comum ocorrer vários ciclos de derrubada e queima da vegetação em áreas de pousio e subsequente cultivo de culturas anuais, em sistema tradicional de agricultura de subsistência e o potencial de conservação dessas florestas é elevado nas regiões antropizadas (VIEIRA; GARDNER, 2012). No Pará, nos últimos anos, as florestas secundárias receberam proteção adequada para sua conservação. De acordo com a aprovação da Instrução Normativa n⿳⺈ 8, de 28 de outubro de 2015, as florestas secundárias de início de sucessão devem ser preservadas em propriedades rurais no Pará. É nessa perspectiva que Vieira et al., (2014) ressaltam a importância de uma legislação que regulamente a supressão de florestas secundárias para produção, pois florestas em estágio sucessional 
avançado, acima de 20 anos de idade, tem o potencial de recuperar parte da biomassa e biodiversidade de uma floresta madura. No caso de Moju, seria importante acompanhar se os produtores da região estão seguindo a legislação estadual (SEMAS, 2015).

Quanto às classes de floresta degradada e a palma de óleo, notou-se que dos usos da terra, estes foram os que mais aumentaram suas áreas no período estudado. De acordo com o IBGE (2015), em Moju, entre 2010 a 2013, houve um aumento significativo de área plantada de dendê na ordem de 27,50 mil hectares para 34,6 mil hactare e algumas diretrizes ambientais que fundamentam o PPSPO estabelecem a proibição da supressão de vegetação nativa, a exclusão de áreas de conservação, o não estabelecimento de novos plantios em áreas com desmatamento de floresta primária após o ano de 2006 e a implantação das áreas produtivas de forma a evitar a ocorrência de plantios contínuos (monoculturas) entre duas ou mais unidades produtivas e a uniformização da paisagem (CARDOSO; TOLEDO; VIEIRA, 2014).

Neste estudo, notou-se um discreto aumento de área do plantio de palma de óleo, para as três áreas analisadas: 0,73\% (Ubá), 3,68\% (Arauai) e 0,79\% (Mamorana). Benami et al. (2018) mostram que o plantio do dendezeiro ocorreu preferencialmente em áreas de florestas secundárias e com pouca intensidade em florestas primárias. De qualquer forma, o monitoramento e controle dessa expansão tornam-se fundamental para a sustentabilidade das regiões envolvidas, pois a sustentabilidade ambiental, econômica e social são pilares a serem estabelecidos para a sustentabilidade de uma região.

A classificação do ITA, nas áreas analisadas (Ubá, Arauaí e Mamorana), apresentou desempenho regular (2,5 - 5,0) e degradado (5,0 - 7,5) (Figura 4). Esse desempenho remete à din1âmica de uso da terra e de logistica de produção de dendê encontrado na área. O desenvolvimento histórico/espacial dessa região levou a uma variedade dos tipos de uso da terra, fragmentando cada vez mais a paisagem. Duas (Ubá e Arauai) das três áreas analisadas obtiveram ITA acima de 5,0 caracterizando fortes indícios de áreas alteradas, propicias ao cultivo do dendezeiro.

Quanto à região de Moju, o plantio da palma de óleo vem se expandindo ao longo dos anos. Esse fato ocasiona transformações de usos da terra (ALMEIDA et al., 2014), e parte dessa expansão se encontra nas áreas de agropecuária ou de florestas secundárias.

Esse mesmo resultado foi encontrado por Almeida (2015) na região de Moju, que por meio de trajetórias do desmatamento no período de 22 anos, 
ficou claro que até 1995 a retirada da floresta era intensa para o plantio da palma de óleo, com aproximadamente 12\% em conversão direta de floresta primária para a palma de óleo. No entanto, para os anos posteriores todas as conversões ocorreram a partir de florestas secundárias e áreas com agopecuária.

Em 2017, o ITA apontou para Arauai e Mamorana o desempenho degradado, ou seja, a região apresentou maior intensidade no uso. Esse resultado demonstrou que houve uma pressão maior na área Mamorana, que em 2013 apresentou desempenho regular e em 2017 foi classificada como degradada. Esses resultados retratam as transformações e as mudanças de uso da terra que estão ocorrendo na parte sul da região de Moju onde está localizada a área Mamorana. Vale ressaltar que a área Ubá permaneceu estável com desempenho regular, mas se percebe que houve um acréscimo sutil de 0,32 no valor do ITA.

No que diz respeito às classes agropecuária e a palma de óleo, que nos anos estudados apresentaram uma maior ocupação do uso da terra, nota-se que em 2017 a classe agropecuária continua a se destacar como a de maior extensão de área, mas já se nota que o antropismo avança nas classes de floresta degradada e floresta secundária.

Em relação às áreas investigadas, ressalta-se que Arauai é uma região de uso da terra consolidado, pois o plantio de dendezeiro data da década de 1980 e possui 15\% de floresta primária e 25,55\% de floresta degradada (Tabela 4). Contudo, essa área não se apresenta estável. De acordo, com o resultado da pressão antrópica, houve uma diminuição de 2013 para 2017, em uma proporção de 0,31, mas na classificação do ITA, a área permanece como degradada (Figura 4).

\section{CONCLUSÕES}

Os resultados apoiam parcialmente a hipótese de que a expansão de palma de óleo leva à intensa transformação antrópica da paisagem nas áreas estudadas. Houve redução na área de remanescentes florestais entre 2013 e 2017, mas a expansão do plantio de palma de óleo não foi muito significativa nesses anos. A transformação antrópica foi considerada regular, ou seja, a pressão na paisagem não foi muito intensa, embora Arauai e Mamorana tenham apresentado maiores pressões antrópicas na paisagem com as áreas consideradadas degradadas sendo derrubadas para a plantação de longo prazo. De qualquer forma, aponta-se a necessidade de ações imediatas para controle do desmatamento e de proteção das florestas remanescentes. 


\section{AGRADECIMENTOS}

As autoras agradecem o apoio do INCT/Biodiversidade e Uso da Terra na Amazônia (Processo CNPq no 574008/2008-0) pelo financiamento para a realização desta pesquisa. Agradecemos também aos especialistas ambientais da Coordenação de Ciências da Terra e Ecologia do Museu Paraense Emílio Goeldi: Jorge Luis Gavina Pereira, Marcelo Cordeiro Thales, Jessica Adrian Lima Farias e Gil Mendes Sales e ao Programa de Pós-Graduação de Geografia, da Universidade Federal do Pará, pelo apoio acadêmico.

\section{REFERÊNCIAS}

ADAMS, J. B. Classification of multispectral images based on fractions of endmembers: Application to land-coverchange in the Brazilian Amazon. Remote Sensing of Environment, v. 52, n. 2, p. 137-154, 1995.

ALMEIDA, A. S. de. Mudanças de uso da terra em paisagens agrícolas com palma de óleo (Elaeis guineensis Jacq.) e implicações para a biodiversidade arbórea na Amazônia Oriental. 2015. Tese (Doutorado em Ciências Ambientais) - Instituto de Geociências, Universidade Federal do Pará, Museu Paraense Emílio Goeldi, Empresa Brasileira de Pesquisa Agropecuária, Belém, 2015.

ALMEIDA, A. S. de.; VIEIRA, I. C. G. Dinâmica da cobertura vegetal e uso da terra no município de São Francisco do Pará (Pará, Brasil) com o uso da técnica de sensoriamento remoto. Bol. Mus. Par. Emílio Goeldi, Belém, v. 3, n. 1, p. 81-92, 2008.

ALMEIDA, A. S. de.; VIEIRA, I. C. G. Conflitos no uso da terra em Áreas de Preservação Permanente em um polo de produção de biodiesel no Estado do Pará. Rev. Ambient. Água, n. 3, sep. 2014.

ALMEIDA, A. S. de.; VIEIRA. I. C. G.; BARROS, M. N. R.; ROCHA E. D. P. N. Áreas de endemismo Belém e Xingu: configuração e espacialização do uso da terra e da cobertura vegetal. In: EMILIO, T.; LUIZÃO, F. (Org.). Cenários para a Amazônia: clima biodiversidade e uso da terra. Manaus: INPA, 2014. p. 57-66

ALVES, D. S., MORTON, D. C., BATISTELLA, M., ROBERTS, D. A.; SOUZA JR., C. The changing rates and patterns of deforestation and land use in Brazilian Amazonia. In: KELLER, M.; BUSTAMANTE, M.; GASH, J.; DIAS, P. S. (Ed.). Amazonia and global change. Washington: American Geophysical Union, 2009. p. 11-24.

BACKHOUSE, M. A desapropriação sustentável da Amazônia: caso de investimentos em dendê no Pará, Fair Fuels? Working Paper 6, Berlin, p. 31, 2013.

BARLOW, J.; GARDNER, T. A.; ARAUJO, I. S.; ÁVILA-PIRES, T. C.; BONALDO, A. B.; COSTA, J. E.; PERES, C. A. Quantifying the biodiversity value of tropical primary, secondary, and plantation forests. Proceedings of the National Academy of Sciences, v. 104, n. 47, p. 18555-18560, 2007. 
BENAMI, E.; CURRAN, L. M.; COCHRANE, M.; VENTURIERI, A.; FRANCO, R.; KNEIPP, J.; SWARTOS, A. Oil palm land conversion in Pará, Brazil, from 2006-2014: evaluating the 2010 Brazilian Sustainable Palm Oil Production Program. Environmental Research Letters. v. 13, n. 3, 034037, 2018.

BRANDÃO, F.; SCHONEVELD, G. The state of oil palm development in the Brazilian Amazon: trends, value chain dynamics, and business models. v. 198. CIFOR, 2015.

CARDOSO, A. S.; TOLEDO, P. M. de; VIEIRA, I. C. G. Dimensão Institucional da Sustentabilidade e Gestão Ambiental no município de Moju, Pará: uma aplicação do Barômetro da Sustentabilidade. Sustentabilidade em Debate, Brasília, v. 5, n. 1, p. $117-$ 135, jan/abr. 2014.

CRUZ, C. B. M., TEIXEIRA, A. J. A., BARROS, R. S., ARGENTO, M. S. F., MAYR, L. M.; MENEZES, P. M. L. Carga antrópica da bacia hidrográfica da Baía de Guanabara. In: SIMPÓSIO BRASILEIRO DE SENSORIAMENTO REMOTO, 9., 1998, Santos. Anais [...]. Santos: INPE, 1998. p. 99-109.

EMBRAPA. A cultura do dendê. Brasília: EMBRAPA, 1995. p. 68

GARDNER, T. A. et al. A social and ecological assessment of tropical land uses at multiple scales: the Sustainable Amazon Network. Phil. Trans. R. Soc. B, v. 368, n. 1619, p. 2-11, 2013.

GOUVEIA, R. G. L.; GALVANIN, E. A. S.; NEVES, S. M. A. S. Aplicação do índice de Transformação Antrópica, na análise multitemporal da Bacia do Córrego do Bezerro Vermelho em Tangará da Serra-MT. Revista Árvore, Viçosa, v. 37, n. 1, p. 1045-1054, 2013.

HOMMA, A. K. O; VIEIRA, I. C. G. Colóquio sobre dendezeiro: prioridades de pesquisas econômicas, sociais e ambientais na Amazônia. Amazônia: Ciência \& Desenvolvimento, Belém, v. 8, n. 15, p. 79-90, 2012.

HUDSON, W. D.; RAMM, C. W. Correct formulation of the kappa coefficient of agreement. Photogrammetric Engineering \& Remote Sensing, v. 53, n. 4, p. $421-$ 422. 1987.

IBGE. Manual Técnico da Vegetação Brasileira. Rio de Janeiro: IBGE, 1991. p. 92.

IBGE. Manual Técnico em Geociências. Rio de Janeiro: IBGE, 1992. p. 44.

IBGE. Banco de Dados Agregados. Sistema IBGE de Recuperação Automática SIDRA. Disponível em: http://www.ibge.gov.br. Acesso: 15 out. 2015.

IDESP. Estatística municipal do Moju. Belém: IDESP, 2013. Disponível em: http:// www.idesp.pa.gov.br/paginas/produtos/EstatisticaMunicipal/pdf/Moju.pdf Acesso em: 23 jan. 2018.

INPE. Projeto PRODES. Disponível em: www.dpi.inpe.br/prodesdigital/ prodesmunicipal.php. 2017. Acessos em: 27 ago. 2018 e 15 jul. 2019. 
LAMB, D.; GILMOUR, D. Rehabilitation and restoration of degraded forests: Issues in Forest Conservation. Switzerland, 2003. p. 122.

LANDIS, J.; KOCH, G. G. The measurements of agreement for categorical data. Biometrics, v. 33, n. 3, p.159-179. 1977.

LEES, A. C.; MOURA, N. G.; ALMEIDA, A. S. de.; VIEIRA, I. C. G. Poor Prospects for Avian Biodiversity in Amazonian Oil Palm. PLOS ONE, v. 10, n. 5, e0122432, 2015.

LÉMECHEV, T. On hydrological heterogeneity catchment morphology and catchment response. Journal of Hydrology, v. 100, p. 375-375, 1982.

MATEO, J. Geoecologia de los paisajes. Caracas: Universidad Central de Caracas, 1991.

NAHUM, J. S.; SANTOS, C. B. Uma interpretação geográfica da dendeicultura na Amazônia paraense. Revista da Anpege, v. 11, n. 15, p. 309-331, 2015.

NOGUEIRA, C. R., CRUZ, C. B. M., AGAREZ, F. V.; VICENS, R. S. Classificação de bacias hidrográficas em tabuleiros costeiros através de indicadores provenientes de sensoriamento remoto-estudo de caso em Linhares e Sooretama, ES. In: SIMPÓSIO BRASILEIRO DE SENSORIAMENTO REMOTO, 10., 2001, Foz do Iguaçu. Anais [...]. Foz do Iguaçu: INPE, 2001. p. 955-958.

PPM. Produção da Pecuária Municipal. 2018. https://www.ibge.gov.br/ estatisticas/economicas/agricultura-e-pecuaria/9107-producao-da-pecuária municipal. htmledicao $=22651 \& \mathrm{t}=$ resultados. Acesso em: 20 jul. 2019.

RIVERO, S.; ALMEIDA, O.; ÁVILA, S.; OLIVEIRA, W. Pecuária e desmatamento: uma análise das principais causas diretas do desmatamento na Amazônia. Nova Economia, Belo Horizonte, v. 19, n. 1, p. 41-66, jan./abr. 2009.

ROCHA, S. P.; CRUZ, C. B. M. Aplicação do ITA na análise espaço-temporal do entorno da BR-101 nos municípios de Angra dos Reis e Parati. In: SIMPÓSIO BRASILEIRO DE SENSORIAMENTO REMOTO, 14., 2009, Natal. Anais [...]. Natal: INPE, 2009. p. $1505-1512$.

SCHWENK, L. M.; CRUZ, C. B. M. Conflitos socioeconômico-ambientais relativos ao avanço do cultivo da soja em áreas de influência dos eixos de integração e desenvolvimento no Estado de Mato Grosso. Acta Scientarium Agronomy. v. 30, p. 501-511, 2008.

SEMAS. Secretaria de Estado de Meio Ambiente e Sustentabilidade. Instrução Normativa SEMAS n⿳o 8, de 28.10.2015. Limpeza e autorização de supressão de vegetação secundária em estágio inicial de regeneração nos imóveis rurais, no âmbito do Estado do Pará. Belém: SEMAS, 2015. Disponível em: http://www.semas.pa.gov. br/2015/11/03/instrucao-normativa-no-08-de-28-deoutubro-de-2015/. Acesso em: 05 dez. 2015.

SILVA, A. de B. Sistemas de Informações Geo-referenciadas: conceitos e fundamentos. Campinas: Unicamp, 1999. p. 15 
SOUZA JR., C. M.; SIQUEIRA, J. V. N. Img'Tools: a software for optical remotely sensed data analysis. In: SIMPÓSIO BRASILEIRO DE SENSORIAMENTO REMOTO, 16., 2013, Foz do Iguaçu, Anais [...]. Foz do Iguaçu: INPE, 2013. p. 13-18.

TEIXEIRA, A. J. A.; CRUZ, C. B. M. Classificação de bacias de drenagem com o suporte do sensoriamento remoto e geoprocessamento caso da Baía de Guanabara. In: SIMPÓSIO BRASILEIRO DE SENSORIAMENTO REMOTO, 7., 2005, Goiânia. Anais [...]. Goiânia: INPE, 2005. v. 12, p. 16-21.

USGS. Landsat Project Description. 2013. Disponível em: http://landsat.usgs.gov/ about_project_descriptions.php. Acessos em: 12 jul. 2014.

USGS. Landsat Project Description. 2017. Disponível em: http://landsat.usgs.gov/ about_project_descriptions.php. Acessos em: 12 jul. 2017.

VIEIRA, I. C. G.; GARDNER, T. A. Florestas secundárias tropicais: ecologia e importância em paisagens antrópicas. Boletim do Museu Paraense Emílio Goeldi. Ciências Naturais, Belém, v. 7, p. 3, 2012.

VIEIRA, I. C. G.; SILVA, J. M. C. da; TOLEDO, P. M. de. Estratégias para Evitar a Perda de Biodiveridade na Amazônia. Estudos Avançados, São Paulo, v. 19, n. 54, p. 153-164, 2005.

VIEIRA, I.; GARDNER, T. A.; FERREIRA, J.; LEES, A.; BARLOW, B. J. Challenges of Governing Second-Growth Forests: A Case Study from the Brazilian Amazonian State of Para. Forests, v. 5, p. 1737-1752, 2014. 